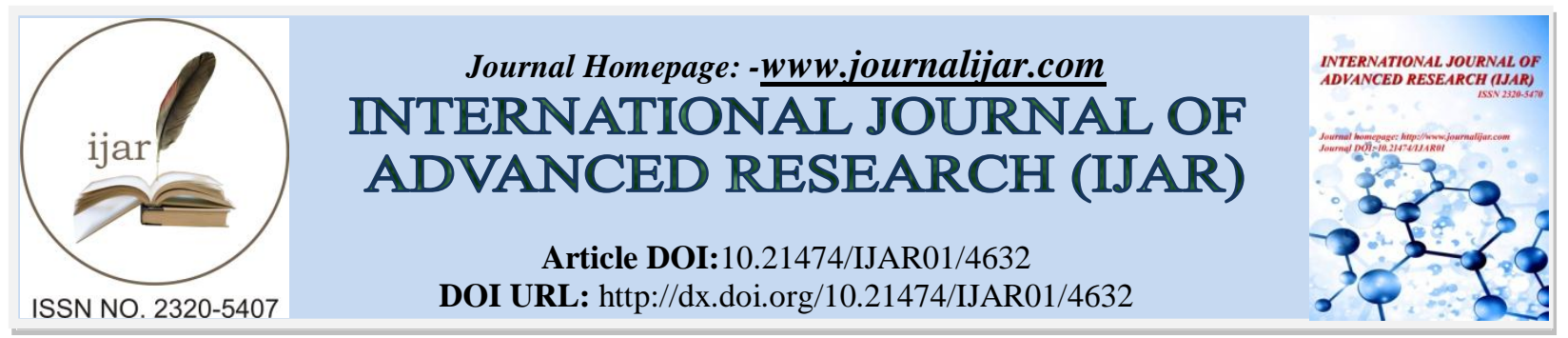

RESEARCH ARTICLE

\title{
PROJECT MANAGERS FORWARD SHIFT ON MANAGEMENT AREAS ALIGNING PROCESS GROUPS RESULTING A PROFITABLE SOFTWARE PROJECT.
}

Vallabhajosyula Bala Naga Venkata Sai ${ }^{1}$, G.V. Bhanu Sai Prasad ${ }^{1}$ and Dr. Kiran Kumar Reddi ${ }^{2}$.

1. Research Scholar, Rayalaseema university, Kurnool India.

2. Department of Computer Science, Krishna University, Machilipatnam.

\section{Manuscript Info}

Manuscript History

Received: 27 April 2017

Final Accepted: 29 May 2017

Published: June 2017

Key words:-

Project Management, Profitability,

Process, Successful projects, Predict

\begin{abstract}
Projects, Project Manager \& Profitability are always being used in common everywhere. Most of the times, project managers work on scheduling, production and communication, if are deeply involved in building team skills having a strategic vision of tactical execution of project leads to a profitable completion of the project. In this paper we discuss on the proposed project management areas if considered helps the project manager as well the organization to enjoy the success and profits of the respective projects. Here we can see how the project management areas, are to be considered and the time of the project passing through the respective project management process areas, and to align the management areas. Project Manager is described in this paper as the person who encourages the engagement of every stakeholder irrespective whether they are team member or CEO or a client, and communicates openly.
\end{abstract}

Copy Right, IJAR, 2017,. All rights reserved.

\section{Introduction:-}

As everyone knows Software Project management focuses on the four very important P's: People, Product, Process and Project. A successful venture is the one where the Project Manager emphasizes on building the right product using the right Process, for the right project, with efficient stake-holder involvement.

The Project Manager directs or guides every stake holder team to know about the execution of their roles, feels empowered and supported in the role, knows the roles of the other team members and acts upon the belief that those roles will be performed. Project management requires that the project manager understands and uses the knowledge and skills on the below P's

1. People

2. Product

3. Process

4. Project

Adding to the above derived P's, this paper speaks additionally how a project manager, updates on the extended P's defined below.

1. Project Charter

2. Procurement 
3. Planning

4. Proactive (Risk Management)

5. Project closure

What is Project Management Area?

This paper considers all the P's as the Project management areas and speaks on how the project manager handle all these management areas to bring a successful and profitable outcome. Project management is a methodical approach of planning and guiding project processes from start to finish. According to the Project Management Institute, the processes are guided through five stages: and are Initiating, Planning, Executing, Monitoring and control, and closing.

\section{DETAILED STUDY ON Management Areas:- People:-}

The people involved in the respective projects are considerable assets, who work, drive, guide, and promote the success and helps in achieving the outcome to be more profitable.

Traditional project management methodologies such as PMP or Price2, define stakeholders as some impacted or affected by the project. In scrum everything is different. Officially scrum recognizes three roles

(a) Development Team/ Team- responsible for turning/converting the requirements into functionality.

Team will work on each project via "sprints" short phases of work which deliver with in the short time.

Teams constantly assess the scope and direction of their product or project. This means that they can change direction at any time in the process to make sure that their product will meet changing needs. Because of this, however, it can be difficult to write a business case at the outset, because the final outcome is not fully known.

(b) Scrum Master- responsible for the managing process. These persons solve the problem, so that product owner can drive development, and maximize ROI. The scrum master ensures that each sprint is self-contained.

Traditionally, the project manager is a leader, a decision maker, a planner, someone who manages the project and the team and is the person accountable to the business for accomplishing the project objectives. The Scrum Master's role is more that of coach and facilitator, a role that sits between the project and the customer. The Scrum Master doesn't manage the team thatproduces the work; instead, he supports the product owner, coaches the team, and makes sure that Scrum processes areadhered to. The Scrum Master is responsible for the Scrum process, its correct and continuous implementation, and the maximization of its benefits.

(c) Product owner: - He is the expert on the product being developed. he or she is the represents the key stake holders customers, and end users, and is responsible for prioritizing the project and getting funding.

Every software project is populated by people who fall within this taxonomy.

Co-ordination and communication issues amongst stake holders

Many a reasons the software projects ended up in troubles, when is a large or complex, lead to confusion and lands up difficulties in communication areas.

Working with cross-functional teams has become a key characteristic when working with People.

Failures in the project or project failures are not because of a lack of technical skills on the part of those executing the project. This is because of inadequate co-ordination, integration, communication and control of project activities amongst the stake holders.

A project manager need to deal communication efficiently, the team which supports the project manager's tasks must adhere the effective methods and coordination amongst need to head the top of chart.

To accomplish this, mechanism for formal and informal communication among team members and with crossfunctional teams need to be charted appropriately. 
Formal communication can be accomplished through writing, structured meetings, and other relatively noninteractive and impersonal communication channels.

Informal communication is more personal. Encouraging the team for sharing the/their ideas on an adhoc basis. Raise a flag among the teams when a problem arises, and can interact with every team member's randomly a standup discussion.

\section{Product:-}

In a confronted dilemma at the very beginning of a software engineering project, A software project manager has to examine the product very closely to understand the problem it is intended to solve. In other words, the scope needs to be defined by the project manager in the initiation phase.

Product must be defined in a written document, which clarifies the product features, internal and external interfaces and ancillary products. Similarly, a resultant GAP analysis is strongly recommended. The software to be purchased must perform what the defined products need, at least through workarounds and customization. Important features should be realized straightaway by the system. External development is to be held in a minimum scale.

A detailed analysis of Procurements would provide necessary information for estimates, but analysis often takes weeks or months to complete. And procurements are frequently changed on the project run.

\section{Process:-}

The generic phases that characterize the software process - definition, development, and support - are applicable to all software. The problem is to select the process model that is appropriate for the software to be engineered by a project team.

1. The Linear Sequential Model

2. The Prototyping Model

3. The Spiral Model

4. The Fourth Generation Technique Model

5. Iterative Water fall model.

6. SCRUM/Agile.

Project manager upon the finalization of the requirements and based on the customer deliverables need to estimate what type of model is applicable and can also go on a mix of models as a better approach to work on the respective product. The estimated model or approach is presented to the stake holders and after a common conclusion it is to be followed.

After the finalization of the process model, project manager should come up with the project plan based on the set of common process frame work activities. Once the preliminary plan is established, process decomposition begins. That is, a complete plan, reflecting the work tasks required to populate the frame work activities must be created.

An effective process mapping should delineate functional roles, process steps and detailed content of process steps. It should highlight the system-related activities and, data inputs and outputs at these activities. It should also define system printouts. Analysts and business specialists must analyze the process a number of times, there by moving from less to more detailed levels. By conducting a careful GAP analysis, analysts can identify the needs for future work-around and customization. External development is to be avoided as much as possible.

A software process provides the framework from which a comprehensive plan for software development can be established.

A small number of framework activities are applicable to all software projects, regardless of their size or complexity.

A number of different task sets-task; milestones, work products, and quality assurance points- enable the framework activities to be adapted to the characteristics of the software project and the requirements of the project team. 
Finally, the umbrella activities - such as software quality assurance, software configuration management, and measurement - overlay the process models.

Umbrella activities are independent of any one framework activity and occur throughout the process.

\section{Project:-}

Ten signs that indicate that the software project management is in jeopardy are:

1. Software people don't understand their customer's needs.

2. The product scope is poorly defined.

3. Changes are managed poorly.

4. The chosen technology changes.

5. Business needs change [or are ill-defined]

6. Deadlines are unrealistic.

7. Users are resistant.

8. Sponsorship is lost [or was never properly obtained].

9. The project team lacks people with appropriate skills.

10. Managers avoid best practices and lessons learned.

A five-part common sense approach to Software Projects is followed as a rescue/ prevention measure 1. Start on the right foot.

2. Maintain Momentum

3. Track Progress

4. Mark Smart decisions

5. Conduct a Postmortem analysis.

\section{Project Charter:-}

A project charter is like bible to the project manager. It contains the process and artifacts of the clear vision and state of the project and it have the key goals and requirements. It captures the customer expectations and gives the clear cut idea on the project resources and the roles, who will perform which role in the project in the high level structure and based on the project needs. It defines or establishes all the resource needs and overall cost targets to complete the project. It will have the WB Structure.

To prepare a project charter document we need the few inputs those are Project Statement of Work, Business Case, Agreements, Enterprise environmental factors, Organization Process Assets.

The tools and techniques which are used to create the project charter document is expert judgment and facilitation techniques by using the inputs and the tools we will get the output as project charter's

\section{Procurements:-}

Project requirements are developed within the process as needs and uses emerge. This could mean that the finaloutcome is different from the one envisaged at the outset.

When it comes to any type of project, requirement collection plays a key role, Requirements collection not only important for the project, but also for the project management function.

There needs to be a clear and better understanding of the project what is eventually to be delivered and is critical to the success. As it is known the requirements plays a vital role in determining the end deliverables of the project an utmost attention is required.

Although requirements collection looks quite straightforward, surprisingly, this is one of the project phases where most of the project starts with the wrong footage. In general, major unsuccessful stories about the projects conclude the wrong or insufficient details and procurements gathering. 


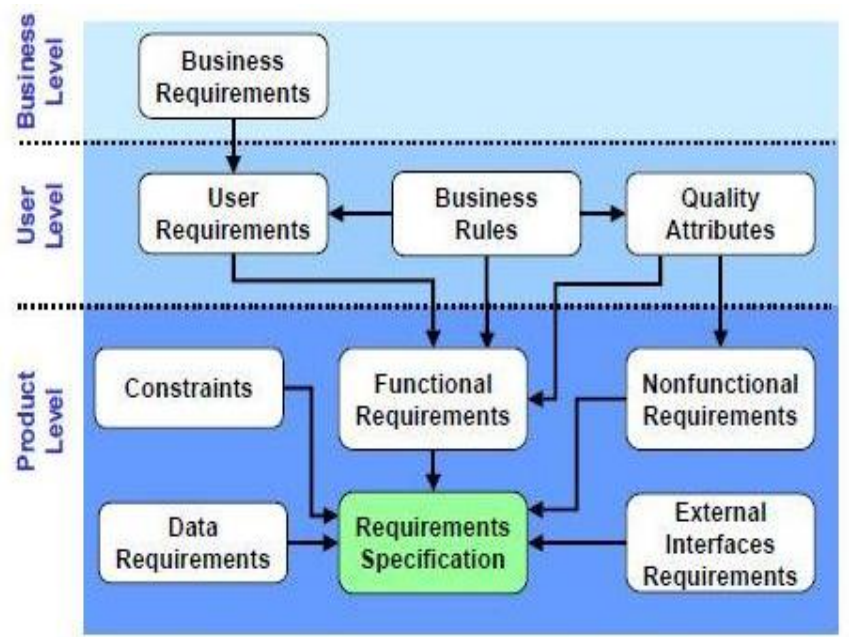

Figure 1 Levels and types of requirements

Types and levels of requirements

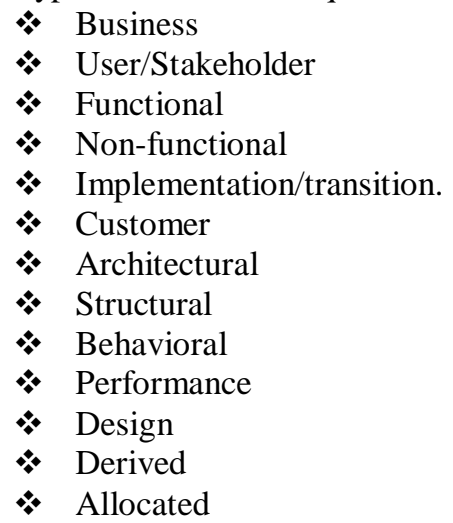

According to bowfins, requirements have 3 levels - business, user and product. Each of them focuses on a different aspect of the problem at hand. For example - business requirements are usually about defining the business problem and target outcome.

A Project Manager can consider the following points while doing Procurement Management

1. Capture $100 \%$ of Requirements

2. Proactively Verify Requirements

3. Ensure Completeness of Requirements

4. Prioritize Requirements Systematically

5. Communicate to teams and cross-functional

6. Trace Dependencies

7. Change request to change control board.

\section{Planning:-}

In general, poor planning is one of the top sources of problems.

How can the poor project planning be avoided?

Project manager can follow the below mentioned points to avoid poor planning.

1. Effective planning, if required consider expert suggestions.

2. Planning based on realistic assumptions.

3. Proper planning of Risk.

4. Individual Plan for Individual Project

5. Planning about the unfolded decisions. 
6. Planning not to diverge from the initial Project plan.

7. Planning about the resource competencies.

8. Learning from the past project plan's.

To overcome the adverse situations, proper care needs to plan for the worst case scenarios and the corresponding responses to be considered in the planning phase. Like,

* A buffer of $15 \%$ to be considered as buffer can be applicable when to mitigate the risk.

* Knowledge sharing sessions to be planned in the team as well cross-functional teams.

- Effective use of lags in the tasks.

* Prioritization of tasks.

A project manager can face below mentioned challenges during project planning.

* Squeezed deadlines, as there is no alternative because it's a compliance requirement.

* Resource movement across projects, so planning of resource backup need to be identified.

* Identifying the backup resources for each module and proper training need to be given.

- Tasks distribution needs a little attention such that there can be more than single resource in any module or feature. This is to avoid dependencies.

* Change requests are inevitable, plan for handling the requirement changes in the planned time.

* Better planning on quality as this plays a key role in success. Plan for if any squeezed schedules.

\section{Proactive:-}

Software engineers are eternal optimists. When planning software projects, we often assume that everything will go exactly as planned. Or, we take the other extreme position: the creative nature of software development means we can never predict what's going to happen, so what's the point of making detailed plans? Both of these perspectives can lead to software surprises, when unexpected things happen that throw the project off track. In my experience, software surprises are never good news.

Risk management, a best practice in the software industry for reducing the surprise factor. While we can never predict the future with certainty, we can apply structured risk management practices to peek over the horizon at the traps that might be looming, and take actions to minimize the likelihood or impact of these potential problems. Risk management means dealing with a concern before it becomes a crisis. This improves the chance of successful project completion and reduces the consequences of those risks that cannot be avoided

A software project may encounter various types of risks:

$\square \square \square$ Technical risks include problems with languages, project size, project functionality, platforms, methods, standards, or processes. These risks may result from excessive constraints, lack of experience, poorly defined parameters, or dependencies on organizations outside the direct control of the project team.

$\square \square \square$ Management risks include lack of planning, lack of management experience and training, communications problems, organizational issues, lack of authority, and control problems.

$\square \square \square$ Financial risks include cash flow, capital and budgetary issues, and return on investment constraints.

$\square \square \square$ Contractual and legal risks include changing requirements, market-driven schedules, health \& safety issues, government regulation, and product warranty issues.

$\square \square \square$ Personnel risks include staffing lags, experience and training problems, ethical and moral issues, staff conflicts and productivity issues.

$\square \square \square$ Other resource risks include unavailability or late delivery of equipment \& supplies, inadequate tools, inadequate facilities, distributed locations, unavailability of computer resources, and slow response times.

Classifying Software Risks

In this section software engineering project risks are categorized. Software project risks can affect requirements, scheduling, cost, quality and business. Therefore, classification on the basis of these groups can be done. From A to E represent these classifications. These risks are gotten through studies and experiences in projects.

\section{Software Requirement Risks.}

* Lack of analysis for change of requirements.

* Lack of report for requirements.

* Ambiguity in requirements.

* Inadequate requirements 
* Invalid requirements.

* Change request

* Poor definition of requirements

* Non-achievable change requests

Software Cost Risks.

* Lack of good estimation in projects.

* The hardware does not work well

* Lack of testing

* Complexity of architecture

* Extension of requirements change.

* Personnel change.

* Technology change.

* Lack of reassessment of management cycle

* Unrealistic schedule

* Human errors

* Lack of monitoring

* Large size of architecture.

* The tools does not work well

* Management change

* Environment change.

\section{Software Scheduling Risks.}

* Inadequate knowledge about tools

* Long-term training for personnel

* Lack of enough skill

- Lack of accurate system domain definition

* Difficulty to implementation

* Lack of tools or tools failure

* Human errors

* Slow management Cycle

\section{Software Quality Risks.}

* Inadequate documentation

* Lack of design documentation

* Lack of enough skill

* Lack of good estimation in projects

- Lack of employment of manager experience.

* Inadequate knowledge about programming language.

* Weakness of management.

- Lack of roles and responsibilities definition

* Lack of collaboration between developer

* Lack of a good guide line

* Lack of commitment

* Unrealistic schedule.

* Lack of reassessment.

\section{Software Business Risks.}

* The products that no one wants, the products those are not suitable strategy.

* The products that sellers do not know how to sell

* Failure in total budget.

- Failure in commitment.

* Failure in management because of change in different people. 


\section{Project Closure:-}

Project Closure involves handing over the deliverables to your customer, passing the documentation to the business, cancelling supplier contracts, releasing staff and equipment, and informing stakeholders of the closure of the project.

After the project has been closed, a Post Implementation Review is completed to determine the project's success and identify the lessons learned.

The activities taken to close a project and the templates which help you to complete each activity are shown in the following diagram. Click the links below to learn how these templates can help you to close projects efficiently

\section{Findings:-}

Most of findings highlighted this approach of aligning the management areas discussed in this paper to align the project management process groups to yield a successful and profitable project.

The mentioned management areas were accepted by Software people across different organizations. A detailed questionnaire is presented to them, and got mixed responses on the proposed solution. After analyzing the received data the mapping of management areas to the process areas as mentioned below.

1. Initiation Phase - Procure, Project charter, Product

2. Planning Phase - Planning, Proactive

3. Execution Phase - People, Project

4. Monitoring \& Control Phase - Process

5. Closure Phase - Project closure



\section{Conclusion:-}

Project manager is the most important and responsible person in delivering a successful product or a project. A project manager normally follows different methods for completing a project. This paper presents about concentrating of the management areas making the end product to be profitable. This paper also explains where these management areas are linked to the project management life cycle phases. This link is proposed such that it doesn't deviate the normal project management life cycle. Easy to remember, that helps in simplifying the complexities of project management. Eliminating complexity in turn reduces variation, which according to quality gurus such as W. Edwards Deming improves quality, reduces expenses and increases productivity. This paper suggests, there exists a lot of scope for extending further research beyond the above management areas, explaining in detail.

\section{References:-}

1. Marcus T. Project management an introduction. URL:http://www.newgrange.org/FTP/pm.ppt

2. Teamworks. Project management. URL:http://www.vta.spcomm.uiuc.edu/PMT/pmt-ov.html

3. ISDP. What is project management? URL:http://itprojmngt.8m.net/projman/pm_what.html 
4. Project Management Institute. Project management-a proven process for success. URL: http://www.pmi.org/projectmanagement/success.htm

5. TenStep Project Management Process. The value of project management. URL:http://www.tenstep.com/0.0.1\%20Home\%20-\%20Value.htm

6. Hoffer JA, George JF, Valacich JS. Managing the information systems project. In:Modern Systems Analysis \& Design. Upper Saddle River, NJ:Prentice Hall, 2002, pp 59-92

7. ISDP. Role description project manager. URL:http://itprojmngt.8m.net/projman/organization/functions/jd_project_manager.html

8. Ford J. Workplace conflict: facts and figures. URL:http://mediate.com/workplace/ford1.cfm

9. Ford J. The training of conflict resolution skills in the workplace. URL:http://www.mediate.com/workplace/workedit3.cfm

10. Capozzoli TK. Conflict resolution-a key ingredient in successful teams. Supervision (60:11), 1999, pp 14-16

11. Wall JA Jr, Callister RR. Conflict and its management. Journal of Management(21:3), 1995, pp 515-558

12. Dana D. What's a conflict? URL:http://www.mediate.com/articles/dana1.cfm

13. Klunk SW. Conflict and the dynamic organization. Hospital Materiel Management Quarterly (19:2), 1997, pp $37-44$

14. Teamworks. Using team conflicts. URL:http://www.vta.spcomm.uiuc.edu/TCT/tctll-ov.html

15. Van Slyke EJ. Resolve conflict, boost creativity HRMagazine(44:12), 1999, pp 132-137

16. Cloke K, Goldsmith J. Conflict resolution that reaps great rewards. The Journal for Quality and Participation(23:3), 2000, pp 27-30

17. Lloyd SR. Conflict resolution: steering clear of the drama triangle. Rural Telecommunications(20:5), 2001, pp 30-34

18. Barnett E. Managing conflicts in systems development. Hospital Materiel Management Quarterly(18:4), 1997, pp 1-6

19. Kerzner H. Conflicts. In:Project Management: A Systems Approach to Planning, Scheduling, and Controlling. New York, NY:John Wiley \& Sons, 2001, pp 379-408

20. Friedman RA, Tidd ST, Currall SC, Tsai JC. What goes around comes around: the impact of personal conflict style on work. International Journal of Conflict Management(11:1), 2000, pp 32-55

21. Rahim MA, Manger NR, Shapiro DL. Do justice perceptions influence styles of handling conflict with supervisors?: what justice perceptions, precisely. International Journal of Conflict Management(11:1), 2000, pp 9-31

22. Barki H, Hartwick J. Interpersonal conflict and its management in information system development. MIS Quarterly(25:2), 2001, pp 195-225

23. Al-Tabtabai H, Alex AP, Aboualfotouh A. Conflict resolution using cognitive analysis approach. Project Management Journal(32:2), 2001, pp 4-16

24. http://en.wikipedia.org/wiki/Project_manager

25. 1. Project Management: Strategic Design \& Implementation, 5th Ed., (2006) David I. Cleland and Lewis R. Ireland

26. 2. Project Manager's Portable Handbook, 2nd Ed. (2004) David I. Cleland and Lewis R. Ireland

27. http://pmtips.net/project-control/

28. http://www.made4u.info/wp9/

29. http://www.interworks.com/blogs/mmedici/2010/01/29/project-management-how-deal-changes-project

30. http://www.usask.ca/its/services/itproject_services/managing_projects/life_cycle.php 